\title{
Transcutaneous carbon dioxide measurement is not a reliable alternative to arterial blood gas sampling in the acute medical setting
}

To the Editor:

Measurement of the arterial carbon dioxide tension $\left(\mathrm{PaCO}_{2}\right)$ is essential in a variety of acute clinical settings and it is often necessary to monitor changes in $\mathrm{PaCO}_{2}$ over time rather than just a one-off measurement. The current gold standard of measuring $\mathrm{PaCO}_{2}$ is arterial blood gas (ABG) sampling but the collection of arterial blood is invasive and associated with complications [1]. To avoid frequent arterial stabs, arterial lines are sometimes placed, but these result in the requirement for level 2 care and are associated with significant risks $[2,3]$. Transcutaneous carbon dioxide tension $\left(\mathrm{PtcCO}_{2}\right)$ has been used in the field of sleep medicine and nocturnal monitoring of carbon dioxide using the transcutaneous method is widely recognised. The technique is noninvasive, low-risk, requires minimal training and is well tolerated $[4,5]$. However, it is not known if $\mathrm{PtcCO}_{2}$ can be used as a reliable measure of $\mathrm{PaCO}_{2}$ in the acute setting, and the evidence to date supporting its use has been contradictory and from small studies of selected patient groups [6-8], who were often medically stable [9]. Patients being treated with noninvasive ventilation (NIV) are often those who require the most frequent $A B G$ monitoring and the recent UK National Confidential Enquiry into Patient Outcome and Death review of NIV care in the UK [10] highlighted the need for careful and timely review of $\mathrm{PaCO}_{2}$ in these patients. An arterial line can help avoid distress to the patient but increased pressure on resources and level 2 beds means that this is not always available, and patients may therefore have to be subjected to repeated arterial stabs. Therefore, we hypothesised that $\mathrm{PtcCO}_{2}$ would be reliable, easy to use and preferred by patients as a means of measuring carbon dioxide in the acute, unselected medical setting.

Medical patients admitted to hospital acutely unwell who required at least one ABG test were eligible to participate. Patients were identified and approached consecutively from acute medical admissions patient lists. Ethical approval for the study was obtained (Regional Ethics Committee 17/LO/1137: IRAS 228887). Written consent, demographic and clinical data were collected. Patients completed a questionnaire about their experience of both techniques.

The procedure for ABG sampling (both arterial stab and collection of blood from arterial lines) was carried out in the standard way either by the researcher or by the clinical team. ABGs were only taken at a time that was clinically indicated as determined by the clinical team. A Resmed SenTec monitor (SenTec AG, Therwil, Switzerland) was used to measure the $\mathrm{PtcCO}_{2}$. Details of the standard set up and calibration of the machine can be found at www.sentec.ch.tv. In brief, the technique involves the machine being used in its "spot check" mode and placement of an electrode sensor on the forehead of the patient. The sensor takes $\sim 15$ min to equilibrate before it will give a $\mathrm{PtcCO}_{2}$ reading. The arterial blood was sampled at the point at which the machine delivered the equilibrated reading.

Bland-Altman analysis calculating the actual difference versus the mean was used to compare paired readings of $\mathrm{PaCO}_{2}$ and $\mathrm{PtcCO}_{2}$ (Prism 6; GraphPad, La Jolla, CA, USA); 95\% limits of agreement were calculated with a pre-determined value of $0.25 \mathrm{kPa}$ as an acceptable difference. The difference between the measurements was then correlated (Pearson's correlation) with clinical parameters to determine any potentially influencing factors. The direction of change between two consecutive paired measurements

@ERSpublications

Transcutaneous $\mathrm{CO}_{2}$ measurement is not a reliable alternative to arterial blood gas sampling in the acute medical setting http://ow.ly/kOll30ntSP1

Cite this article as: Mummery V, Rogers E, Padmanaban V, et al. Transcutaneous carbon dioxide measurement is not a reliable alternative to arterial blood gas sampling in the acute medical setting. Eur Respir J 2019; 53: 1801726 [https://doi.org/10.1183/13993003.01726-2018]. 

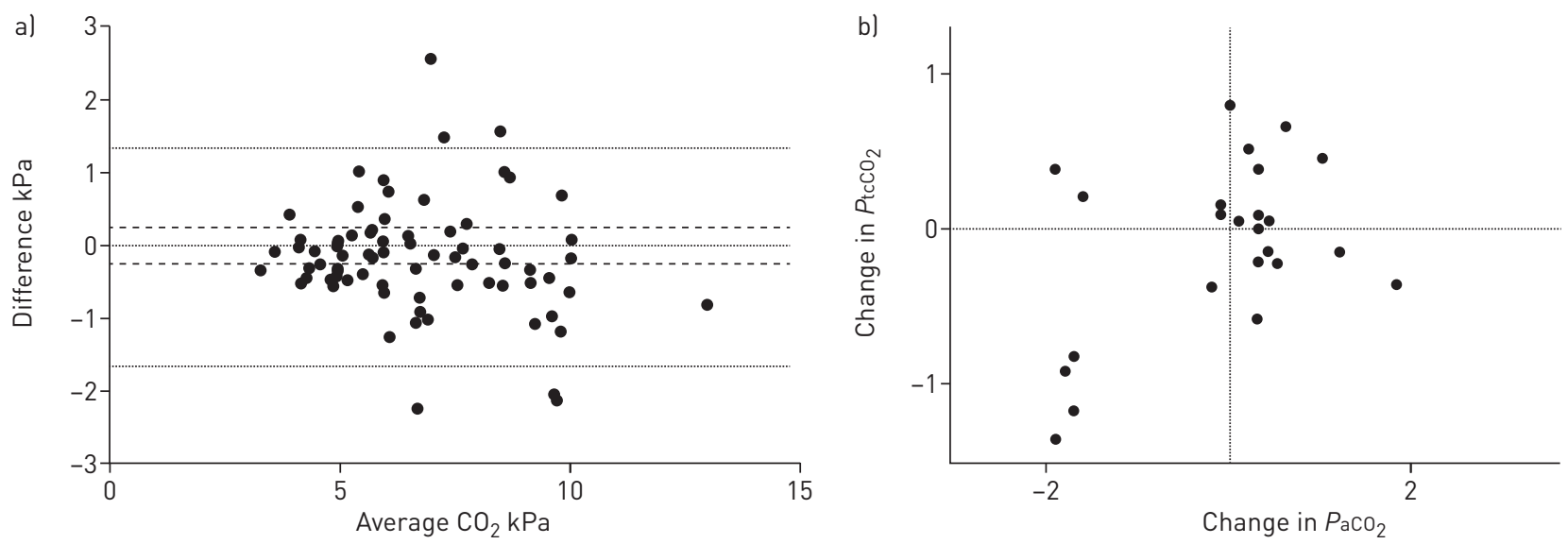

FIGURE 1 a) Bland-Altman plot to show the difference between carbon dioxide measured by transcutaneous monitoring $\left(P_{\mathrm{tc}} \mathrm{CO}_{2}\right)$ and arterial blood gas analysis $\left(\mathrm{PaCO}_{2}\right)$ versus the mean of the two measurements. $\mathrm{n}=74$. Dotted lines: $95 \%$ limits of agreement $(-1.67-1.35 \%)$; dashed lines: clinically acceptable difference $( \pm 0.25 \mathrm{kPa})$. b) Graph to show direction of change in carbon dioxide between two consecutive measurements in the same patient when measured by transcutaneous carbon dioxide monitoring versus arterial blood gas analysis. $\mathrm{n}=24$.

within the same patient was compared between the two techniques of measuring carbon dioxide (i.e. where more than one paired sample was taken from the same patient at different time points, the question was asked "did the carbon dioxide change in the same direction when measured by each technique?"). Patient experience was analysed qualitatively.

50 participants ( 23 males; median age 68 years, range 17-90 years) were recruited and consented to the study (72 screened; five patients did not require further ABG and 17 were unwilling or unable to consent). 45 patients completed the questionnaire; the five remaining were unable to partake in this element of the study due to their medical condition. Patients were admitted to hospital for a range of diagnoses: respiratory problems were most common (27 out of 50,) followed by nonrespiratory sepsis (seven out of 50), then cardiovascular (five out of 50) and the remaining 11 were admitted with other medical diagnosis (including neurological, diabetic and general medical issues). 74 paired samples $\left(\mathrm{PtcCO}_{2}\right.$ and $\left.\mathrm{PaCO}_{2}\right)$ were collected; no one participant had more than four pairs of samples. The following clinical data were collected at the time of the carbon dioxide measurements: median (range) temperature $36.7^{\circ} \mathrm{C}\left(35.7-38.4^{\circ} \mathrm{C}\right.$ ), oxygen saturations $93 \%(83-100 \%)$, heart rate 88 beats per min (60-100 beats per min) and mean arterial blood pressure $86 \mathrm{mmHg}$ (53-109 mmHg). The ABG measurements showed a median $\mathrm{PaCO}_{2}$ of $6.45 \mathrm{kPa}$ (3.4-13.4 kPa) and the $\mathrm{PtcCO}_{2}$ measurements $6.36 \mathrm{kPa}(3.1-12.6 \mathrm{kPa})(\mathrm{n}=74$ for both).

Bland-Altman analysis suggested that the bias of the $\mathrm{PtcCO}_{2}$ tended to be $0.16 \mathrm{kPa}(95 \% \mathrm{CI} \pm 1.54 \mathrm{kPa})$ lower than the $\mathrm{PaCO}_{2}$ with $95 \%$ limits of agreement $-1.67-1.35 \mathrm{kPa}$ (figure 1a). The difference between the two measurements was compared to the mean arterial blood pressure, heart rate, temperature and oxygen saturations; none of these parameters was found to affect how much the $\mathrm{PtcCO}_{2}$ measurement differed from the $\mathrm{PaCO}_{2}$ (data not shown). 24 samples were collected consecutively; however, in only $54 \%$ of cases (13 out of 24) did the carbon dioxide change in the same direction when measured by the two techniques (figure 1b).

Patients overwhelmingly found the $\mathrm{PtcCO}_{2}$ measurement more tolerable than the arterial stab. No patients reported any pain, and the only other comments were three patients out of 45 reporting a feeling of "warmth on the skin" during the $\mathrm{PtcCO}_{2}$ measurement and one complaining of slight heaviness where the probe was stuck to the skin. Arterial stabs were reported as painful and unpleasant (eight patients had arterial lines and, therefore, did not comment on arterial stabs; 33 reported significant pain and the remaining four reported minor pain or a scratch.) Patients reported dreading arterial stabs where as $100 \%$ (45 out of 45) said that they would have $\mathrm{PtcCO}_{2}$ measurements in the future.

$\mathrm{PtcCO}_{2}$ is an attractive option for the measurement of carbon dioxide; it is noninvasive, allows the patient to be managed in a low-acuity area and requires little skill to carry out. Other studies have variably shown that $P \mathrm{tcCO}_{2}$ may [6,7] or may not [8] be a reliable alternative to the gold standard $\mathrm{ABG} P \mathrm{PaCO}_{2}$. This larger, real-world study, recruiting unselected acutely unwell patients with a range of diagnoses, demonstrates that $\mathrm{PtcCO}_{2}$ should not be used as an alternative to the ABG to monitor carbon dioxide levels. The limitations to the study include the fact only a Resmed SenTec monitor was tested and only the forehead position was used for placement of the sensor; other devices or sensors in other positions may show other results. However, in this study the limits of agreement for the two techniques of measuring $\mathrm{PtcCO}_{2}$ were not only 
wide but also lay significantly outside what may be an acceptable difference of $\pm 0.25 \mathrm{kPa}$. This is in line with previous work [11]. Furthermore, the $\mathrm{PtcCO}_{2}$ could not be reliably used to suggest a trend or direction of change in carbon dioxide level. This is disappointing both for staff and patients, as our qualitative patient analysis clearly demonstrated that $\mathrm{PtcCO}_{2}$ is a much more tolerable technique than ABG sampling. The study did not test whether either method of measuring carbon dioxide tension can be used to predict clinical outcomes or direct clinical decisions; the study question was limited only to whether the two methods of measuring carbon dioxide have comparable and clinically reliable results, so further research would be needed to answer this question. In conclusion, the results of this study suggest that $\mathrm{PtcCO}_{2}$ measured by this method should not be used in the acute clinical setting as an alternative to the $\mathrm{PaCO}_{2}$ measured by ABG sampling. Health economic pressures and patient experience considerations continue to call for more work to be done to find an alternative to the ABG.

Victoria Mummery ${ }^{1,2}$, Eleanor Rogers ${ }^{1}$, Vijay Padmanaban ${ }^{1}$, Dionne Matthew ${ }^{2}$, Thomas Woodcock ${ }^{2}$ and Susannah Bloch

${ }^{1}$ Chest and Allergy Department, Imperial College Healthcare NHS Trust, London, UK. ${ }^{2}$ NIHR CLAHRC Northwest London, Imperial College London, Chelsea and Westminster Hospital, London, UK.

Correspondence: Susannah Bloch, Chest and Allergy department, St Mary's Hospital, Imperial College Healthcare NHS Trust, London W2 1NY, UK. E-mail: susannah.bloch@doctors.org.uk

Received: Sept 102018 | Accepted after revision: Dec 232018

Acknowledgements: T. Woodcock reviewed the statistical analysis.

Conflict of interest: V. Mummery reports grants from CLAHRC NWL during the conduct of the study and that the SenTec $\mathrm{PtcCO}_{2}$ monitor was on loan from Resmed for the duration of the study. E. Rogers has nothing to disclose. V. Padmanaban reports conference sponsorship from Chiesi outside the submitted work. D. Matthew has nothing to disclose. T. Woodcock has nothing to disclose. S. Bloch reports that the SenTec $\mathrm{PtcCO}_{2}$ monitor was on loan from Resmed for the duration of the study.

Support statement: This work was funded through a Collaboration for Leadership in Applied Health Research and Care (CLAHRC) research-driven QI project grant. V. Mummery was funded by this grant. This article presents independent research in part funded by the National Institute for Health Research (NIHR) under the CLAHRC programme for Northwest London. The views expressed in this publication are those of the authors and not necessarily those of the NHS, the NIHR or the Department of Health and Social Care. The work was supported by Resmed who loaned the SenTec machine. Funding information for this article has been deposited with the Crossref Funder Registry.

\section{References}

1 Huttmann S, Windisch W, Storre J. Techniques for the measurement and monitoring of carbon dioxide in the blood. Ann ATS 2014; 11: 645-652.

2 The Intensive Care Society. Levels of Critical Care for Adult Patients. www.ics.ac.uk/AsiCommon/Controls/BSA/ Downloader.aspx?iDocumentStorageKey=74ca75c6-67c4-4400-96a2-4e7e14b8d9a3\&iFileTypeCode=PDF\&iFileName= Levels\%20of\%20Critical\%20Care\%20for\%20Adult\%20Patients. Date last updated: 2009.

3 Garg K, Howell B, Saltzberg S, et al. Open surgical management of complications from indwelling radial artery catheters. J Vasc Surg 2013; 58: 1325-1330.

4 Eberhard P. The design, use and results of transcutaneous carbon dioxide analysis: current and future directions. Int Anaesth Res Soc 2007; 105: 48-52.

5 Aarrestad S, Tollefsen E, Kleiven AL, et al. Validity of transcutaneous $\mathrm{PCO}_{2}$ in monitoring chronic hypoventilation treated with non-invasive ventilation. Respir Med 2016; 112: 112-118.

6 Cox M, Kemp R, Anwar S, et al. Non-invasive monitoring of $\mathrm{CO}_{2}$ levels in patients using NIV for AECOPD. Thorax 2005; 61: 363-364.

7 Roediger R, Beck-Schimmer B, Theusinger $\mathrm{O}$, et al. The revised digital transcutaneous $\mathrm{PCO}_{2} / \mathrm{SpO}_{2}$ ear sensor is a reliable non-invasive monitoring tool in patients after cardiac surgery. J Cardiothorac Vasc Anaesth 2011; 25: 243-249.

8 Kelly A, Klim S. Agreement between arterial and transcutaneous $\mathrm{PCO}_{2}$ in patients undergoing non-invasive ventilation. Respir Med 2011; 105: 226-229.

9 Parker S, Gibson G. Evaluation of a transcutaneous carbon dioxide monitor ('TOSCA') in adult patients in routine respiratory practice. Respir Med 2007; 101: 261-264.

10 National Confidential Enquiry into Patient Outcome and Death. Inspiring Change. London, NCEPOD, 2017.

11 Kim JY, Yoon YH, Lee SW, et al. Accuracy of transcutaneous carbon dioxide monitoring in hypotensive patients. Emerg Med J 2014; 31: 323-326. 